\title{
MENTES SEQUESTRADAS
}

\author{
J.COSTA JÚNIOR \\ Instituto Federal de Educação, Ciência e Tecnologia de Minas Gerais \\ jose.costajunior@yahoo.com.br
}

Submetido em 17/02/2019 - Aceito em 26/12/2019

DOI: $10.15628 /$ holos.2019.8324

Vivemos numa era em que praticamente todos os aspectos da vida cotidiana possuem uma relação direta ou indireta com a equipamentos de comunicação e a rede mundial de computadores, onde o desenvolvimento das tecnologias de comunicação alteraram radicalmente nossos cotidianos e práticas mais comuns. Definitivamente inseridos em nossas vidas, aparelhos inteligentes estão sempre presentes, solucionando nossas dúvidas, entregando informações sobre as mais diversas temáticas e obtendo nossa atenção de uma forma pouco imaginada há décadas atrás. A tela do telefone celular é a primeira coisa que muitos de nós vemos quando acordamos e a última antes de dormir. Tais aparelhos e seus recursos parecem desenhados para estarem disponíveis e serem necessários à todo momento, tornando-se até mesmo viciantes, com impactos sociais e psicológicos consideráveis. No entanto, passamos a viver em tais condições sem muita análise, mudando nossos hábitos e atividades muitas vezes de forma automática e pouco refletida. Temos assim o desafio de compreender as novas dinâmicas de vida nesse contexto e desenvolvermos uma compreensão mais ampla de nossas atuais circunstâncias.

Nesse contexto, o rápido crescimento no ritmo do desenvolvimento tecnológico que levou a tal estado de coisas estimula uma série de questionamentos acerca de suas possíveis consequências em diversos aspectos, desde temas sociais até questões ligadas ao funcionamento do cérebro e da cognição humanas. Quais são os riscos de uma interação digital tão intensa? Temos tempo para analisar profundamente seus efeitos? E quanto às informações falsas que podem surgir e serem difundidas nos meios digitais? As redes de interação social poderiam estar alterando nossos comportamentos e comunicação com outros seres humanos? Existem efeitos sobre nossa saúde e bem estar? Sociólogos, filósofos, psicólogos sociais e neurocientistas vêm investigando esses impactos e diversas teorias acerca das consequências da imersão tecnológica nos humanos vem sendo formuladas. O debate tem sido intenso, atualizado por novos dados científicos e observações sociais variadas.

Conforme o relato do engenheiro e filósofo americano Tristan Harris, que trabalhou como especialista em desenho de tecnologias na empresa Google durante quatro anos, tais tecnologias são desenhadas e construídas para "explorar nossas vulnerabilidades e tendências psicológicas". Segundo essa análise, as empresas de tecnologia de comunicação obtêm sucesso com seus produtos e aplicativos pois utilizam um vasto conhecimento para "sequestrar nossas mentes e nossa atenção". No entanto, a busca para manter as pessoas constantemente conectadas em seus aparelhos, fazendo uso de aplicativos e mantendo interações sociais digitais, tem gerado efeitos perversos na saúde mental, aumento dos níveis de estresse e ansiedade, juntamente com o surgimento de vícios comportamentais entre os mais jovens. Harris, que foi pesquisador no Laboratório de Tecnologia Persuasiva na Universidade de Stanford, atua hoje como líder do projeto Time Well Spent, que busca desenvolver soluções e incentivar as empresas de tecnologia a considerar o bem estar psicológico e social dos usuários e consumidores. 
Harris foi um dos especialistas entrevistados professor de psicologia e marketing Adam Alter para escrever o livro, aqui resenhado, intitulado Irresistível: por que você é viciado em tecnologia e como lidar com ela, publicado em 2014 nos EUA e em 2018 no Brasil. Trata-se de um ensaio acadêmico que busca mostrar como tecnologias, aparelhos e recursos da rede mundial de computadores nos capturam e viciam, deixando pouca margem para escolha e trazendo sérios impactos para a nossa saúde e bem estar. Alter destaca como os vícios comportamentais se desenvolvem a partir do uso constante de redes e tecnologias construídas especificamente para esse fim. O potencial viciante de tais equipamentos e dispositivos em crianças e adolescentes é exemplificado logo na introdução do livro, no relato de Alter sobre a forte proibição por parte de Steve Jobs de que seus filhos utilizassem tablets e smartphones.

O livro de Alter é dividido em três partes. Na primeira, aborda a natureza do vício comportamental e como ele é construído em nossas mentes, principalmente a partir de expectativas de promessa e recompensa imediatas e reforços positivos. Divididos entre moderados e extremos, os vícios comportamentais podem se desenvolver através do uso repetitivo de smartphones, tablets e internet, quando retomamos repetitivamente o uso dessas tecnologias, sempre em busca de novas informações e interações. Como esses aparelhos estão sempre próximos de nós, a interação é constante e pode levar ao vício comportamental. Alter destaca também o fato de que todos nós estamos disponíveis para vícios, principalmente se o contexto favorecer tais dinâmicas. Traz exemplos de soldados americanos que lutaram na Guerra do Vietnã e se viciaram em álcool e outras drogas, uma vez que estavam inseridos em ambientes que estimulavam tais comportamentos. O mesmo acontece com o vício em tecnologias: determinados contextos e ambientes podem ser propícios ao uso constante e reiterado, que pode levar ao desenvolvimento de rotinas comportamentais viciantes. A biologia e a estrutura do cérebro são impactadas e alteradas por tais rotinas, que impactam decisivamente a saúde e o bem estar e promovem o desenvolvimento do vício.

Na segunda parte, Alter aborda o que chama de "ingredientes do vício comportamental", ou os modos através dos quais se elabora uma experiência viciante. Destaca seis elementos fundamentais para tal estruturação: (i) o estabelecimento de metas através da experiência; (ii) o retorno (feedback) através da interação constante; (iii) uma escalada de progresso na interação; (iv) um aumento considerável nos níveis de dificuldade e sofisticação; (v) as ligações entre as partes das circunstâncias onde o indivíduo opera; (vi) as interações sociais envolvidas. Videogames, redes sociais, serviços de streaming e aplicativos diversos, entre outros, fazem uso recorrente de tais moldes, utilizando-se de padrões e dinâmicas psicológicas próprias, que nos faz manter a atenção e concentração voltadas para tais elementos. Um traço fundamental de nossa espécie, o sono natural, é muito impactado por essa situação, uma vez que passamos a dormir cada vez mais tarde.

$\mathrm{Na}$ terceira e última parte, Alter aborda algumas soluções para os problemas originados pela relação viciante entre nós e as tecnologias de interação digital, mostrando possibilidades e caminhos. $\mathrm{O}$ autor reconhece a dificuldade de manter crianças e adolescentes longe de tais elementos, mas recomenda que os responsáveis estejam atentos aos modos e às rotinas das interações. Faz referência à "arquitetura comportamental", uma tentativa de estimulação de rotinas e comportamentos que podem evitar ou diminuir o impacto de interações tecnológicas entre jovens e adultos, mas também reconhece seus limites. A partir do desenho de circunstâncias e ambientes, a possibilidade de vícios comportamentais pode ser diminuída, uma vez que regulase e controla-se o ambiente. Entre tais medidas, Alter cita o distanciamento de tecnologias (colocar o celular para carregar fora do quarto), o estabelecimento de metas e objetivos em relação ao tempo uso, e a gamificação, isto é, a construção de jogos e simulações com o objetivo de diminuir o impacto das interações digitais. 
Alter não demoniza as redes sociais, os jogos eletrônicos e as tecnologias em geral no livro, mas destaca o modo como as tecnologias são construídas, considerando as tendências psicológicas e comportamentais dos seres humanos, com o objetivo de nos manter cada vez mais frequentes nas interações digitais. No entanto, ressalta o risco de produzir vícios comportamentais que as telas e tecnologias possuem, dadas as finalidades de suas construções. Mais importante, chama a atenção para os riscos envolvidos no uso constante de tais elementos, que impactam nossas condições psicológicas e de saúde de forma direta. Ainda não sabemos exatamente a dimensão desse impacto, mas ele é inegável. As diversas pesquisas e investigações às quais Alter faz referência em seu ensaio apontam para mudanças consideráveis em nossas mentes, muitas das quais temos pouca consciência.

Irresistivel é um livro muito bem vindo nesse momento em que estamos cada vez mais conectados e interagindo através da Internet. Uma observação crítica sobre o livro é que Alter é muitas vezes rápido em análises importantes, principalmente em relação às questões políticas envolvidas. Deveríamos limitar o acesso de jovens à rede? As empresas de tecnologia deveriam ser submetidas a algum tipo de controle? Como o livro de Alter é curto, é possível que tais análises mais amplas tenham ficado em segundo plano. No entanto, são questões importantes do nosso tempo, que em impactos sociais e políticos das tecnologias e seus efeitos são cada vez mais destacados.

A cultura ocidental é construída em torno de ideais de escolha individual, autonomia e liberdade. No entanto, as empresas de tecnologia estão cada vez mais informadas acerca das nossas tendências e vieses, explorando-as para obter informações e lucro oferecidos por nós em troca de "curtidas". Dessa forma, nada parece mais distante da realidade nesse contexto do que a expectativa de soberania que ideais de individualidade e liberdade esperam. Muitas vezes viciados, limitados e cada vez mais presos às nossas telas, corremos o risco de perder os resquícios de liberdade que ainda possuímos. Mais do que compreender os efeitos das novas tecnologias como importantes questões de saúde pública, trata-se de reconhecer que nossas vidas estão sendo alteradas por interações digitais e tecnológicas muito além de nossa consciência e controle, desenhadas por especialistas que nos conhecem mais do que nós mesmos.

\section{REFERÊNCIAS}

ALTER, Adam (2018). Irresistível: por que você é viciado em tecnologia e como lidar com ela. Tradução de Cássio de Arantes Leite. Rio de Janeiro: Objetiva. 